\title{
Optimum assembly line balancing: A stochastic programming approach
}

\author{
Dilip Roy $^{\mathrm{a}^{*}}$ and Debdip khan
}

${ }^{a}$ Department of Business Administration, The University of Burdwan, Golapbag. Burdwan W.B., India

${ }^{b}$ Department of Business Administration, Burdwan Raj College, Golapbag. Burdwan, India

\begin{tabular}{|c|c|}
\hline A R T I C L E I N F O & A B S T R A C T \\
\hline $\begin{array}{l}\text { Article history: } \\
\text { Received } 1 \text { June } 2010 \\
\text { Received in revised form } \\
9 \text { July } 2010 \\
\text { Accepted } 9 \text { July } 2010 \\
\text { Available online } 10 \text { July } 2010 \\
\text { Keywords: } \\
\text { Slackness, } \\
\text { Assembly line } \\
\text { System loss } \\
\text { Balancing loss } \\
\text { Integer Programming }\end{array}$ & $\begin{array}{l}\text { Assembly line balancing problem is an approach of assigning a set of tasks to an ordered } \\
\text { sequence of workstations. This assignment needs to be made in such a way that the } \\
\text { underlying precedence constraints are not violated and efficiency measures are optimized } \\
\text { subject to the restriction of the cycle time constraint. Research works, reported so far, mainly } \\
\text { deal with the minimization of balancing loss, subject to precedence constraints. Lack of } \\
\text { uniqueness in those optimum solutions and pressing demand to include system loss in the } \\
\text { objective function have led to the present work of minimization of both balancing and system } \\
\text { loss. As there is no standard measure for system loss, the current work proposes a measure } \\
\text { for system loss and offers solution to this bi-objective problem. }\end{array}$ \\
\hline
\end{tabular}

\section{Introduction}

\subsection{Literature review}

Traditional production methods have been gradually replaced by assembly line method because high volume and low cost production have been the need of the day. Balancing of assembly line to ensure a high rate of output is a difficult optimization problem. This optimization problem is further restricted by precedence constraints and the problems of divisibility of work elements. Bringing down this level of complexity to a solvable state is the simplest approach followed in operations research to solve a line balancing problem, which in reality is very complex in nature. Given a set of tasks of various durations, a set of precedence constraints among the tasks, and a set of workstations, one has to assign each task to exactly one workstation in such a way that no precedence constraint is violated and the assignment is optimal in some sense (Becker and Scholl 2006). There are basically two types of problems addressed so far in assembly line balancing. First, for a given cycle time, the number of workstations is to be minimized such that the cycle time cannot be exceeded by the total task time of work elements assigned to any of the workstations. Second, with a given number of workstations, the cycle time is to be minimized where the cycle time is equal to the largest total task time of the work elements, assigned to a workstation. Attempts to solve the optimization of these two variants of line balancing problems started during 1950s. That time, the focus of attention was on the core problem of configuration, which is the assignment of tasks to workstations. Bowman (1960) was the first to work

\footnotetext{
* Corresponding author. Tel. +919434331371 Fax +913422559774
}

E-mail addresses: debdip.khan@gmail.com (D. Khan) 
on that. He considered the linear programming approach to arrive at an optimum solution to the line balancing problem. After that, different optimization techniques were proposed to solve the problem of line balancing. To present a clear formulation of the problem for arriving at the solution, Hoffman (1963), Mansoor and Yadin (1971) and Geoffrion (1976) used mathematical programming approach. Baxey (1974) emphasized on the configuration of multiple workstations. Vrat and Virani (1976) presented a cost model for optimal mix of balanced stochastic assembly line and the modular assembly system for a customer oriented production system. Van Assche and Herroelen (1979) proposed an optimal procedure for the single-model deterministic assembly line balancing problem. Later, Graves and Lamer (1983) used Integer programming procedure for designing an assembly system. Talbot and Patterson (1984) used a similar technique to solve the assembly line balancing problems. Sarin and Erel (1990) developed a cost model for the single-model stochastic assembly line balancing problem for the objective of minimizing the total labor cost and the expected incompletion cost arising from tasks not completed within the prescribed cycle time. For the multi-product assembly line balancing problem, Berger et al (1992) adopted Branch-and-bound algorithms and Suresh and Sahu (1994) addressed the problem of balancing assembly lines with stochastic task processing times using simulated annealing. The study of Nkasu and Leung (1995) adopted the methodology of stochastic modeling, whereby various probability distributions are integrated within a modified COMSOAL algorithm, as a means of addressing the uncertainties associated with key assembly line balancing variables, such as cycle time and task times. Pinnoi and Wilhelm (1998) used the branch and cut approach for system design. Nicosia et al. (2002) introduced the concept of cost and studied the problem of assigning operations to an ordered sequence of non-identical workstations, which also took into consideration the precedence relationships and cycle time restrictions. Their purpose was to minimize the cost of the assignment by using a dynamic programming algorithm. Erel et al. (2005) presented a beam search-based method for the stochastic assembly line balancing problem in U-lines. Zhao et al. (2006) dealt with sequence-to-customer goal with stochastic demands for a mixed-model assembly line to minimize the number of stations and task duplication costs in the mixed-model assembly line balancing problem and Bukchin and Rabinowitch (2006) proposed a branch-and-bound based solution. Agarwal and Tiwari (2008) proposed a collaborative ant colony algorithm to stochastic mixed-model U-shaped disassembly line balancing and sequencing problem. Gamberini et al. (2009) presented a multiple single-pass heuristic algorithm to solve the stochastic assembly line rebalancing problem developed to find the most complete set of dominant solutions representing the Pareto front of the problem.

\subsection{Problem description}

Minimization of balancing loss or cost of assignment was the only important consideration in all the above mentioned methods. These methods can be best used in the case of transfer lines because in a transfer line, elements are preferably performed by machines. Assembly lines involving human elements have another pressing problem. "The losses resulting from workers' variable operation times" is known as System loss (see Ray Wild, 2004) and this loss is perhaps more important than the losses resulting from uneven allocation of work elements to workstations. Consequently, the problem of line design is not only the equal division of work among the stations or the adaptation of tasks to the speed of the workers but also to provide some amount of slackness in each workstation to take care of the variability of the elemental times. Our objective in this current work is to design an assembly line where dual objectives of minimization of balancing loss and system loss can be met by switching over from the domain of deterministic set-up to the domain of stochastic set-up. We propose an optimization method based on stochastic programming approach for that purpose.

\section{Notation and Methodology}

\subsection{Notation:}

$\mathrm{E}($.$) \quad statistical expectation operator$

$\mathrm{K}$ number of jobs

$\mathrm{N}$ number of workstations 


$\begin{array}{ll}\mathrm{N}\left(\mu, \sigma^{2}\right) & \text { normal distribution with mean } \mu \text { and variance } \sigma^{2} \\ \mu_{i} & \text { expected task time of } \mathrm{i}^{\text {th }} \text { job } \\ \sigma_{i}^{2} & \text { variance task time of } \mathrm{i}^{\text {th }} \mathrm{job} \\ \tau_{\alpha_{j}} & \text { the upper } \alpha_{j} \text { point of } \mathrm{N}(0,1) \\ \mathrm{t}_{\mathrm{i}} & \text { random task time or assembly time of } \mathrm{i}^{\text {th }} \mathrm{job} \\ \mathrm{W}_{\mathrm{j}} & \mathrm{j}^{\text {th }} \text { workstation } \\ \mathrm{a}(\mathrm{i}, \mathrm{j}) & \text { binary measure taking value } 1 \text { for assignment of task } \mathrm{i} \text { to workstation } \mathrm{j} \\ \mathrm{L}_{\mathrm{j}} & \text { variable idle time of } \mathrm{j}^{\text {th }} \text { work station } \\ \mathrm{N}_{\text {min }} & \text { minimum number of workstation for a given cycle time } \\ \mathrm{C} & \text { cycle time } \\ \mathrm{C}_{\mathrm{t}} & \text { trial cycle time } \\ \mathrm{C}_{\text {min }} & \text { minimum cycle time for a given } \mathrm{K} \\ \mathrm{S}_{\mathrm{t}} & \text { slackness for trial cycle time } \mathrm{C}_{\mathrm{t}}, \mathrm{i} . \mathrm{e} ., \mathrm{S}_{\mathrm{t}}=\mathrm{C}-\mathrm{C}_{\mathrm{t}} \\ \mathrm{B} & \text { balancing loss } \\ \mathrm{V} & \text { variance of idle times, } \mathrm{L}_{1}, \mathrm{~L}_{2}, . ., \mathrm{L}_{\mathrm{N}} .\end{array}$

\subsection{Methodology:}

The main cause of balancing loss, as pointed out earlier, is the uneven allocation of work to different workstations. Generally, to examine the efficiency of an assembly line one uses the concept of balancing loss, $B$. The proposed work of this paper is a multi-objective with two objectives of system and balancing loss. The system loss arises out of workers' variable operation time (Ray Wild 2004). But no standard measure has been proposed so far to examine the extent of system loss. We propose to consider a measure for system loss. As we know, system loss arises out of workers' variable operation time, so any configuration where one workstation has high idle time and another workstation has no idle time will create high disruption. In the deterministic model, set up leads us to consider the variance of the idle times $(V)$ as a measure for system loss for the system. The stability of the total system is on maximum level when this variance is on minimum level (Roy and Khan 2010). Under stochastic task times, the objective of our proposed method is to minimize the expected values of $B$ and $V$, subject to precedence constraints and chance constraints in terms of cycle time.

\section{Mathematical Formulation}

Consider the binary variable $a(i, j)$ such that

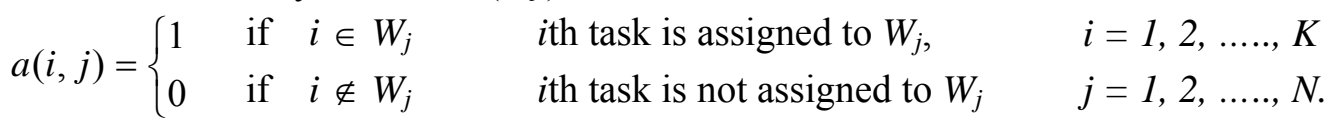

Then, under the condition that the ith task can be assigned to only one workstation, the following condition must hold for all $i=1,2, \ldots ., K$.

$\sum_{j=1}^{N} a(i, j)=1$.

Furtheraccording to precedence constraints if task $i^{\prime}$ is to be assigned before assigning task $i$, that is

$i^{\prime} \prec i$, then $a(i, j) \leq \sum_{r=1}^{j} a\left(i^{\prime}, r\right) \quad \forall \quad i^{\prime} \prec i$

Human beings are involved in completion of tasks involved in assembly line. So, depending upon variations in human skills and behavior, the task time of each job becomes a random variable. Therefore, we need to consider both expected time for completion of each job and the extent of variability. Let $\mu_{i}$ be the expected time for completing $i^{\text {th }}$ job. Then, the expected balancing loss of the system is as follows,

$E(B)=E\left(\frac{N C-\sum t_{i}}{N C}\right) 100 \%$, or $\quad E(B)=\frac{\left(N C-\sum \mu_{i}\right)}{N C} * 100 \%$. 
At the same time, the measure of system is calculated taking the expectation of the variance of random idle times, i.e. $E(V)$. By definition, $V=\frac{1}{N} \sum\left(L_{j}-\bar{L}\right)^{2}$. But $L_{j}$, the idle time in $j^{\text {th }}$ workstation, is $\left\{C-\sum_{i=1}^{N} t_{i} a(i, j)\right\}$. Thus,

$$
\mathrm{V}=\frac{1}{N_{j}} \sum\left[C-\sum_{i=1}^{K} t_{i} a(i, j)-C+\frac{1}{N} \sum_{i=1}^{K} t_{i}\right]^{2}=\frac{1}{N}\left(\sum_{i=1}^{K} t_{i}\left(a(i, j)-\frac{1}{N}\right)\right)^{2} .
$$

Hence the expectation of $\mathrm{V}$ can be simplified as

$$
\left.\begin{array}{rl} 
& E(V)=\frac{1}{N} \sum_{j=1}^{N} E\left(\sum_{i=1}^{K} t_{i}\left(a(i, j)-\frac{1}{N}\right)\right)^{2} \\
= & \frac{1}{N} \sum_{j=1}^{N}\left[\sum_{i=1}^{K} \sum_{h=1(i \neq h)}^{K} E\left(t_{i} t_{h}\right)\left(a(i, j)-\frac{1}{N}\right)\left(a(h, j)-\frac{1}{N}\right)+\sum_{i=1}^{K}\left(\sigma_{i}^{2}+\mu_{i}^{2}\right)\left(a(i, j)-\frac{1}{N}\right)^{2}\right] \\
= & \frac{1}{N} \sum_{j=1}^{N}\left[\sum_{i=1}^{K} \sum_{h=1(i \neq h)}^{K} \mu_{i} \mu_{h}\left(a(i, j)-\frac{1}{N}\right)\left(a(h, j)-\frac{1}{N}\right)+\sum_{i=1}^{K}\left(\sigma_{i}^{2}+\mu_{i}^{2}\right)\left(a(i, j)-\frac{1}{N}\right)^{2}\right] \\
= & \frac{1}{N} \sum_{j=1}^{N}\left[\sum_{i=1}^{K} \sum_{h=1(i \neq h)}^{K} \mu_{i} \mu_{h}\left(a(i, j)-\frac{1}{N}\right)\left(a(h, j)-\frac{1}{N}\right)+\sum_{i=1}^{K}\left(\sigma_{i}^{2}\left(a(i, j)-\frac{1}{N}\right)^{2}+\right.\right. \\
= & \frac{1}{N} \sum_{j=1}^{N}\left[\left\{\sum_{i=1}^{K} \mu_{i}\left(a(i, j)-\frac{1}{N}\right)\right\}^{2}-\sum_{i=1}^{K}\left\{\mu_{i}\left(a(i, j)-\frac{1}{N}\right)^{2}\right)\right] \\
\left.\mu_{i}^{2}\left(a(i, j)-\frac{1}{N}\right)\right\}^{2}+\sum_{i=1}^{K}\left(\sigma_{i}^{2}\left(a(i, j)-\frac{1}{N}\right)^{2}+\right.
\end{array}\right]
$$

Thus,

$\mathrm{E}(\mathrm{V})=\frac{1}{N} \sum_{j=1}^{N}\left[\sum_{i=1}^{K} \mu_{i}\left(a(i, j)-\frac{1}{N}\right)\right]^{2}+\frac{1}{N} \sum_{j=1}^{N} \sum_{i=1}^{K} \sigma_{i}{ }^{2}\left(a(i, j)-\frac{1}{N}\right)^{2}$.

Since the task times are random variables, the condition for completion of tasks in a workstation within the assigned cycle time can be best described in terms of chance constraints is as follows,

$\operatorname{Pr} .\left[\sum_{i=1}^{K} t_{i} a(i, j) \leq C\right] \geq 1-\alpha_{j}$ where $0 \leq \alpha_{j} \leq 1, \quad \mathrm{j}=1,2, \ldots, \mathrm{N}$.

Equivalently it can be expressed as follows,

$\operatorname{Pr} .\left[L_{j} \geq 0\right] \geq 1-\alpha_{j}$

$\operatorname{Pr} \cdot\left[\frac{L_{j}-E\left(L_{j}\right)}{\sqrt{\operatorname{var}\left(L_{j}\right)}} \leq-\frac{E\left(L_{j}\right)}{\sqrt{\operatorname{var}\left(L_{j}\right)}}\right] \geq 1-\alpha_{j}$

or, $1-\Phi\left(-\frac{E\left(L_{j}\right)}{\sqrt{\operatorname{var}\left(L_{j}\right)}}\right) \geq \Phi\left(\tau_{\alpha_{j}}\right)$

or, $\Phi\left(\frac{E\left(L_{j}\right)}{\sqrt{\operatorname{var}\left(L_{j}\right)}}\right) \geq \Phi\left(\tau_{\alpha_{j}}\right)$

Therefore,

$E\left(L_{j}\right) \geq \tau_{\alpha_{j}} \sqrt{\operatorname{Var}\left(L_{j}\right)}$.

Since we have,

$E\left(L_{j}\right)=E\left[C-\sum_{i=1}^{K} t_{i} a(i, j)\right]=\left[C-\sum_{i=1}^{K} E\left(t_{i}\right) a(i, j)\right]=\left[C-\sum_{i=1}^{K} \mu_{i} a(i, j)\right]$ 
and

$$
\begin{gathered}
\operatorname{Var}\left(L_{j}\right)=E\left\{\sum t_{i} a(i, j)-\sum E\left(t_{i}\right) a(i, j)\right\}^{2}=E\left\{\sum\left(t_{i}-E\left(t_{i}\right)\right) a(i, j)\right\}^{2} \\
=\sum a^{2}(i, j) \operatorname{var}\left(t_{i}\right)=\sum a^{2}(i, j) \sigma_{i}^{2} .
\end{gathered}
$$

Using Eq. (6) and Eq. (7), Eq. (5) can be rewritten as,

$$
\begin{aligned}
& E\left(L_{j}\right) \geq \tau_{\alpha_{j}} \sqrt{\operatorname{Var}\left(L_{j}\right)}, \\
& \text { or, } \quad\left[C-\sum_{i=1}^{K} \mu_{i} a(i, j)\right] \geq \tau_{\alpha_{j}} \sqrt{\operatorname{Var}\left(L_{j}\right)}, \\
& \text { or, } \quad C \geq \sum_{i=1}^{K} \mu_{i} a(i, j)+\tau_{\alpha_{j}} \sqrt{\operatorname{Var}\left(L_{j}\right)}, \\
& \text { or, } \quad C \geq \sum_{i=1}^{K} \mu_{i} a(i, j)+\tau_{\alpha_{j}} \sqrt{\sum a^{2}(i, j) \sigma_{i}^{2}} .
\end{aligned}
$$

Thus, the chance constraints regarding cycle time can be reduced to the following deterministic constraints,

$\sum_{i=1}^{K} \mu_{i} a(i, j)+\tau_{\alpha_{j}} \sqrt{\sum a^{2}(i, j) \sigma_{i}^{2}} \leq C$.

Finally, combining Eq. (1) to Eq. (4) and Eq. (9), a deterministic problem for stochastic model formulation of the optimization problem can be written as follows,

$\min \mathrm{E}(\mathrm{B})=\frac{\left(N C-\sum \mu_{i}\right)}{N C}$

$\min \mathrm{E}(\mathrm{V})=\frac{1}{N} \sum_{j=1}^{N}\left[\sum_{i=1}^{K} \mu_{i}\left(a(i, j)-\frac{1}{N}\right)\right]^{2}+\frac{1}{N} \sum_{j=1}^{N} \sum_{i=1}^{K} \sigma_{i}{ }^{2}\left(a(i, j)-\frac{1}{N}\right)^{2}$

subject to

(i) $\sum_{j=1}^{N} a(i, j)=1 \quad \forall i$

(ii) $a(i, j) \leq \sum_{r=1}^{j} a\left(i^{\prime}, r\right) \quad \forall \quad i^{\prime} \prec i$

(iii) $\quad a(i, j)=0,1 \quad \forall i, j$

(iv) $\sum_{i=1}^{K} \mu_{i} a(i, j)+\tau_{\alpha_{j}} \sqrt{\sum a^{2}(i, j) \sigma_{i}^{2}} \leq C . \quad \forall j$

To assign equal importance to each workstation we consider $\alpha_{j}=\alpha \quad \forall j$.

Further $\alpha_{j}$ may be considered 0.05 for which $\tau_{\alpha_{j}}=1.6449$. One way of dealing with dual objective is to combine them with weights or priorities. In that case the reduced objective can be written as follows,

$\min \mathrm{Z}=w_{1} *\left(\frac{\left(N C-\sum \mu_{i}\right)}{N C}\right)+w_{2} * \frac{1}{N}\left(\sum_{j=1}^{N}\left[\sum_{i=1}^{K} \mu_{i}\left(a(i, j)-\frac{1}{N}\right)\right]^{2}+\sum_{j=1}^{N} \sum_{i=1}^{K} \sigma_{i}^{2}\left(a(i, j)-\frac{1}{N}\right)^{2}\right)$,

where $0 \leq w_{1}, w_{2} \leq 1$, and $w_{1}+w_{2}=1$. However, we prefer to sequentially undertake the task of minimization by generating in the first instant feasible solutions under the objective of minimization of $E(B)$ under $w_{1}=1$ and $w_{2}=0$ and then obtaining the final solution by imposing the second objective of minimization of $E(V)$ with $w_{1}=0$ and $w_{2}=1$. To generate the set of feasible solutions we consider a sequential approach of assigning trial cycle time and resulting in slack time, to be assigned to each workstation meeting the optimality condition for the first objective of (10). 


\section{The Algorithm}

To numerically solve the proposed optimization problem we have adopted the following algorithm where the overall problem has been subdivided into sub problems based on trial cycle time. For each trial cycle time, simulation approach has been adopted to arrive at all possible feasible solutions.

1. Calculate the theoretical minimum number of workstations, $\mathrm{N}_{\min }$, using the following,

$$
\sum_{i=1}^{K} \frac{\mu_{i}}{C} \leq N_{\min } \leq \sum_{i=1}^{K} \frac{\mu_{i}}{C}+1
$$

2. Calculate the minimum cycle time, $C_{\min }$, using the relation, $C_{\min }=\left[\sum_{i=1}^{K} \frac{\mu_{i}}{N_{\min }}+1\right]$

3. Set the cycle time at $C_{\min }$

4. Make an attempt to get feasible solution following the algorithm of Roy and Khan (2010) with usual cycle time constraints replaced by (10)(iv)

5. If no feasible solution is obtained then increase $\mathrm{N}_{\min }$ by 1 and go to step 3

6. Within the generated set calculate $E(V)$ for each set and save the $E(V)$ value

7. Compare the $E(V)$ with the previous value of $E(V)$, If the current $E(V)$ is lower than the previous one, then save the current value of $E(V)$

8. When all the feasible sets are over, the final solution to the optimization problem is achieved.

In this sequential simulation method, if the set of feasible solutions is finite we can arrive at global solution. It is analytically difficult to claim global optimality in case solution set is not finite. However the Kuhn Tucker condition being both necessary and sufficient for the problem we may check for optimality.

\section{Worked Out Example}

Consider an assembly line balancing problem from Ray Wild (2004) depicted in Fig 1. where the task number is represented by the figure within a circle.

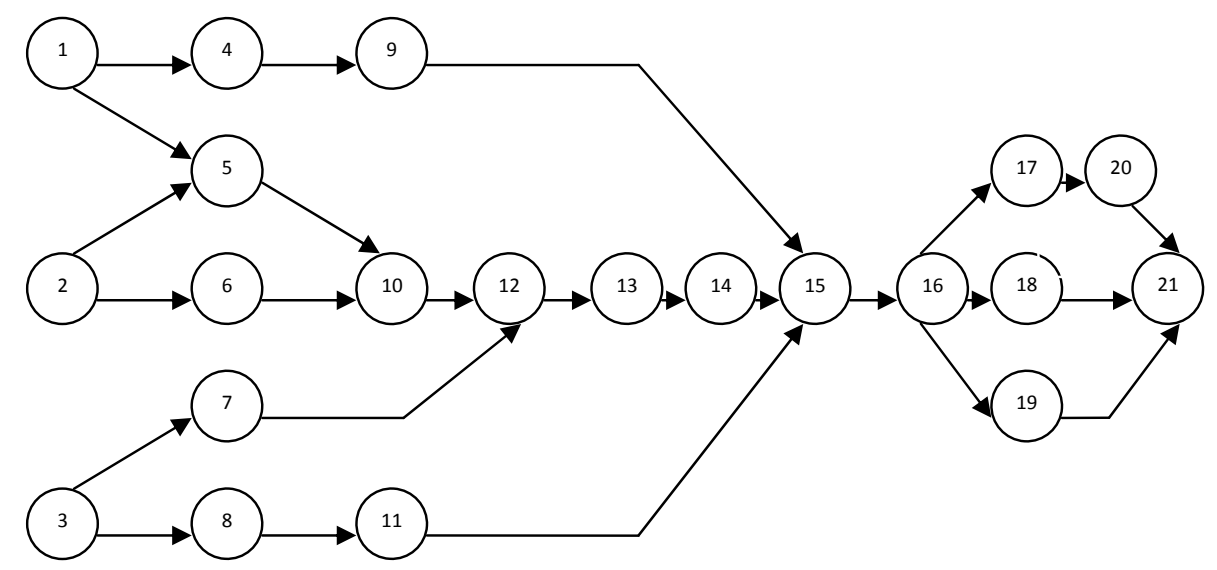

Fig. 1. Precedence diagram of workstations.

This problem is summarized in a tabular form in terms of work elements, immediate predecessor(s), expected task durations and their variability are given in Table 1. For this particular problem, we first get the minimum number of workstations with cycle time $C=35$ with $\mathrm{N}_{\min }=5$. Therefore the minimum trial cycle is $C_{\min }=\left[\sum_{i=1}^{K} \frac{\mu_{i}}{N_{\min }}+1\right]$, i.e. $C_{\min }=29$. Since the cycle time $C$ is 35 , the trial cycle time starts with 29 and goes upto 35 . But among the initial trial cycle times as 29, 30, 31, 32, $33,34,35$ we get the first feasible solution at $\mathrm{C}_{t}=33$. Thus, our trial cycle times are 33,34 and 35 . The final configuration has been obtained from trial cycle time as 34 with slackness $s_{t}=c-c_{t}=1$. This configuration is presented in Table 2. 
Table 1

Precedence relationships and task times of work elements

\begin{tabular}{cccc}
\hline Work element & Immediate predecessor & Expected activity Time & Variance of activity time \\
\hline 1 & - & 6 & 0.09 \\
2 & - & 5 & 0.0625 \\
3 & - & 8 & 0.16 \\
4 & 1 & 9 & 0.2025 \\
5 & 1,2 & 5 & 0.0625 \\
6 & 2 & 4 & 0.04 \\
7 & 3 & 5 & 0.0625 \\
8 & 3 & 6 & 0.09 \\
9 & 4 & 10 & 0.25 \\
10 & 5,6 & 5 & 0.0625 \\
11 & 8 & 6 & 0.09 \\
12 & 10,7 & 2 & 0.01 \\
13 & 12 & 5 & 0.0625 \\
14 & 13 & 4 & 0.04 \\
15 & $9,11,14$ & 12 & 0.38 \\
16 & 15 & 10 & 0.25 \\
17 & 16 & 5 & 0.0625 \\
18 & 16 & 15 & 0.5625 \\
19 & 16 & 10 & 0.25 \\
20 & 17 & 5 & 0.0625 \\
21 & 18,20 & 6 & 0.09 \\
\hline
\end{tabular}

Table 2

Final optimum configuration

\begin{tabular}{lcccccc}
\hline \multicolumn{7}{c}{ Work stations } \\
\hline $\mathrm{C}$ & 1 & 2 & 3 & 4 & 5 & $\mathrm{E}(\mathrm{V})$ \\
34 & $2,3,6,7,8$ & $1,4,5,11$ & $9,10,12,13,14$ & $15,16,19$ & $17,18,20,21$ & 6.707 \\
\hline
\end{tabular}

The optimal configuration consists of 5 workstations with work elements $2,3,6,7,8$ assigned to workstation 1, work elements 1, 4, 5, 11 assigned to workstation 2, work elements 9, 10, 12, 13, 14 assigned to workstation 3, in workstation 4 work elements 15,16, 19 are assigned and work elements 17, 18, 20, 21 assigned to workstation 5 for trial cycle time 34. Finally, the corresponding value of $\mathrm{E}(\mathrm{V})$ comes out as 6.707 .

\section{Conclusion}

A mathematical programming approach is presented for balancing an assembly line with twin objectives of minimization of balancing loss and system loss. As system loss arises out of variations in human behavioral, stochastic setup is needed for describing the situation, representing of the problem and arriving at the final solution of the same. Reduction of the stochastic setup into deterministic constraints has been implemented under normality assumption. A sequential approach has been installed to arrive at the final solution. We believe the approach is generic and it can be used to solve different line assembly problems in reasonable computation time. Final choice can be made based on minimum number of workstations and minimum value of expected variance of the idle times, proposed herein as a measure of system loss.

\section{References}

Agarwal, S. \& Tiwari, M. K. (2008). A collaborative ant colony algorithm to stochastic mixed-model U-shaped disassembly line balancing and sequencing problem. International Journal of Production Research, 46(6), 1405-1429. 
Baxey, G.M. (1974). Assembly line balancing with multiple stations. Management Science, 20(6), 1010-1021.

Becker, C. \& Scholl, A. (2006). A survey on problems and methods in generalized assembly line balancing. European Journal of Operational Research, 168(3), 694-715.

Berger, I., Bourjolly, J-M., \& Laporte, G. (1992). Branch-and-bound algorithms for the multi-product assembly line balancing problem. European Journal of Operations Research, 58(2), 215-222.

Bowman, E.H. (1960). Assembly Line Balancing by Linear Programming. Operations Research, 385-389.

Bukchin, Y. \& Rabinowitch, I. (2006). A branch-and-bound based solution approach for the mixedmodel assembly line-balancing problem for minimizing stations and task duplication costs. European Journal of Operational Research, 174, 492-508.

Erel, E., Sabuncuoglu, I. \& Sekerci, H. (2005). Stochastic assembly line balancing using beam search. International Journal of Production Research, 43(7), 1411-1426.

Gamberini, R., Gebennini, E., Grassi, A. \& Regattieri, A. (2009). A multiple single-pass heuristic algorithm solving the stochastic assembly line rebalancing problem. International Journal of Production Research, 47(8), 2141-2164.

Geoffrion, A. M. (1976). The purpose of mathematical programming is insight, not numbers. Interface, 7(1), 81-92.

Graves, S.C. \& Lamer, B.W. (1983). An integer programming procedure for assembly system design problems. Operations Research, 31(3), 522-545.

Hoffmann, T.R. (1963). Assembly line balancing with precedence matrix. Management Science, 9,551-562.

Mansoor, E.M. and Yadin, M. (1971). On the problem of assembly line balancing. Development in Operations Research, edited by B. Avi-ltzhak, Gordon and Breach, New York, 361.

Nicosia, G., Pacciarelli, D. \& Pacifici, A. (2002). Optimally balancing assembly lines with different workstations. Discrete Applied Mathematics, 118, 99-113.

Nkasu, M. M. \& Leung, K. H. (1995). A stochastic approach to assembly line balancing. International Journal of Production Research, 33(4), 975-991.

Pinnoi, A. \& Wilhelm, W.E. (1998). Assembly system design: A branch and cut approach. Management Science, 44(1), 103-118.

Roy, D. and Khan, D. (2010). Assembly Line Balancing to minimize Balancing Loss and System Loss, Journal of Industrial Engineering international, 11(6).

Roy, D. and Khan, D. (2010). Integrated model for line balancing with workstation inventory management, International Journal of Industrial Engineering Computation, 2(1), 139-146.

Sarin, S. C. \& Erel, E. (1990). Development of cost model for the single-model stochastic assembly line balancing problem. International Journal of Production Research, 28(7), 1305-16.

Scholl, A. (1999). Balancing and Sequencing of Assembly Lines. Second Edition, Physica-verlag Heidelberg.

Suresh, G. \& Sahu, S. (1994). Stochastic assembly line balancing using simulated annealing. International Journal of Production Research, 32(8), 1801-1810.

Talbot, F. B. \& Patterson, J.H. (1984). An integer programming algorithm with network cuts solving the assembly line balancing problems. Management Science, 30(1), 85-99.

Van Assche, F. and Herroelen, W.S. (1979). An optimal procedure for the single- model Deterministic assembly line balancing problem. European Journal of Operational Research, 142.

Vrat, P and Virani, A. (1976). A cost model for optimal mix of balanced stochastic assembly line and the modular assembly system for a customer oriented production system. International Journal of Production Research, 14(4), 445-463.

Wild, R. (2004). Operation Management, Holt, Rinehart and Winston, London.

Zhao, X., Yeung, J. H. Y., \& Xie, J. (2006). Sequence-to-customer goal with stochastic demands for a mixed-model assembly line. International Journal of Production Research, 44(24), 5279-5305. 